This item was submitted to Loughborough's Research Repository by the author.

Items in Figshare are protected by copyright, with all rights reserved, unless otherwise indicated.

\title{
Transnational mobility and the spaces of knowledge production: a comparison of global patterns, motivations and collaborations in different academic fields
}

\section{PLEASE CITE THE PUBLISHED VERSION}

http://dx.doi.org/10.5194/sg-2-97-2007

\section{PUBLISHER}

Copernicus Publications / @ Heike Jons

\section{VERSION}

VoR (Version of Record)

\section{PUBLISHER STATEMENT}

This work is made available according to the conditions of the Creative Commons Attribution-NonCommercialShareAlike 2.5 License (CC BY-NC-SA 2.5) licence. Full details of this licence are available at: https://creativecommons.org/licenses/by-nc-sa/2.5/

\section{LICENCE}

CC BY-NC-ND 4.0

\section{REPOSITORY RECORD}

Jons, Heike. 2019. "Transnational Mobility and the Spaces of Knowledge Production: A Comparison of Global Patterns, Motivations and Collaborations in Different Academic Fields". figshare.

https://hdl.handle.net/2134/4975. 


\title{
Transnational mobility and the spaces of knowledge production: a comparison of global patterns, motivations and collaborations in different academic fields
}

\author{
H. Jöns \\ Department of Geography, Loughborough University, Loughborough, UK \\ Received: 15 December 2006 - Published in Soc. Geogr. Discuss.: 12 February 2007 \\ Revised: 27 September 2007 - Accepted: 18 October 2007 - Published: 14 November 2007
}

\begin{abstract}
Transnational movements of academics shape the production and dissemination of knowledge and thus the geographies of contemporary knowledge economies. In this paper, I investigate the complex relationship between knowledge production and spatial movement by examining three key aspects of academic mobility to Germany in the period 1981 to 2000: first, global patterns of interaction, second, motivations to work in Germany for a limited period of time and, third, resulting publications and collaborations. The study is based on two sets of statistical data and a postal survey involving about 1200 respondents from 90 countries. I argue that the motivations for and outcomes of transnational academic mobility are not only shaped by a great variety of influences that constitute society, academia and the individual but also by varying spatial relations of different research practices, which help to explain typical cultures of academic mobility and collaboration. Drawing upon an actor-network based understanding of both the natural and technical sciences and the arts and humanities, a three-dimensional matrix is developed that conceptualises varying spatial relations of scientific practice and interaction in different fields and at different stages of knowledge production.
\end{abstract}

\section{Introduction}

At a time when the "knowledge economy" is growing in international importance, the global circulation of scientists and scholars appears to be of crucial importance to the competitiveness of modern nation states and individual academic institutions (e.g., Universities UK, 2007). Academic mobility, comprising of mostly circular geographical movements for professional activities such as research stays, guest professorships and conference travel, does not only seem to play

Correspondence to: $\mathrm{H}$. Jöns

(h.jons@lboro.ac.uk) a key role in the internationalisation of higher education and in maintaining a strong research capacity but also in the longterm development of transnational networks within and beyond the academy (Altbach, 1989; Blumenthal et al., 1996; OECD, 1996, 2004; Ackers, 2005). Research on the nature and outcome of academic mobility has important implications for science and higher education policies that govern evaluations of academic performance, international contacts and exchange programmes. It also provides important insights into the geographies of contemporary knowledge economies and related spaces of knowledge production (e.g., Teichler, 2002; Jöns, 2003a).

In this paper, I explore the complex relationship between knowledge production and spatial movement by looking at the ways in which geographical patterns, motivations for and outcomes of transnational academic mobility vary among researchers working in different countries and in different academic fields. I argue that transnational academic mobility is not only shaped by a great variety of influences that constitute society, academia and the individual but also by varying spatial relations of different research practices, which help to explain different cultures of academic mobility and collaboration. An important starting point for this argument is the question of how geography matters in the pursuit of science. While this question has been discussed by Livingstone (2002b, 2003) and others before (e.g., Jöns, 2003a:473), Powell (2007:321) only recently emphasised that it would be important to go beyond the mere statement that geography, or location, matters for scientific practice and to take up the question of how this is the case. In the following, I explore this question from the perspective of travelling scientists from different countries and different academic fields. In order to evaluate how the scientists' needs "and possibilities to reach out from a place of knowledge production in order to communicate, to interact and to mobilise new resources" vary (Jöns, 2003a:473), the paper examines geographical patterns of academic mobility to Germany and the

Published by Copernicus Publications. 
motivations for the related research stays. In order to find out how "the different geographical context at the host compared to the home institution [mattered] in the researchers' work and interaction during their visits" (Jöns, 2003a:471), the paper investigates collaborations between the visiting researchers and their colleagues.

The study is based on three sets of data about the largest sponsorship programme for visiting academics in Germany, which is run by the Alexander von Humboldt Foundation (Bonn). The first set contains data on all granted Humboldt research fellowships in the period 1981 to 2000 . The second includes data on all applications for Humboldt research fellowships in the period 1996 to 2000. The third draws on a postal sample survey of visiting researchers to Germany in the period 1954 to 2001. This survey, conducted at the University of Heidelberg in the year 2003, resulted in 1893 responses from former Humboldt research fellows. ${ }^{1}$ In the following, the analysis focuses on the last two decades of the 20th century by examining the experiences of 1131 Humboldt research fellows from 90 countries. This equals roughly every eighth of all academics who spent their first Humboldt research stay in Germany in the period 1981 to 2000. Methodically, the survey benefited from a previous study on German-American academic relations, which was based on a complete survey of the Humboldt award winner programme (1972-1996) and on more than 60 semistructured interviews with US senior scientists (Jöns, 2003a). The detailed categories of the new questionnaire, constructed out of the rich qualitative data, and the large number of responses to the world-wide survey both provide a unique opportunity for analysing the complexity and dynamics of academic mobility in different fields and types of research work.

\subsection{Conceptual approach}

Drawing upon recent work in science studies and geography, this paper builds upon an actor-network based understanding of scientific work and interaction. Scientific practice is thus being understood as a network-building process between humans and nonhumans. Both are regarded as outcomes and mediators of network-building and thus, by extending human agency to things, are called "actants" (Latour, 1999:180). According to Latour, scientific network-building is characterised by a systematic mobilisation of heterogeneous actants in a few "centres of calculation" that can afford the expensive "proof race" of the sciences (Latour, 1987:179). Inside these centres the accumulated resources are transformed, tied to-

\footnotetext{
${ }^{1}$ In the period 1954 to 2001 , the Humboldt fellowship programme sponsored research stays of 17216 visiting academics in Germany; in 2002, about $90 \%$ of these research fellows were still in contact with the Humboldt Foundation. Every fourth of them received a questionnaire. This resulted in a random sample of 3718 Humboldt research fellows, i.e. every fifth of all Humboldt research fellows in the period 1954 to 2001 . After sending one reminder, the response rate amounted to $51 \%$, or 1893 questionnaires.
}

gether and re-represented in order to build a strong web of associations that makes up a new knowledge claim when all the assembled human and nonhuman allies successfully control one another and thus act as a "black box", a unified whole (Latour, 1987:130-131). By claiming that nonhumans can incorporate both material and social characteristics, actornetwork thought applies a concept of hybridity that acknowledges the hybrid ontological status of sociomaterial things. Through the various processes of network formation such as mobilisation, translation and transformation, nonhuman materialities get socialised and become sociomaterial hybrids with their own (hybrid) historicity (Latour, 1999:212-214). In this respect actor-network theory "makes apparent the impossibility of having an artifact that does not incorporate social relations as well as the impossibility of defining social structures without accounting for the large role played in them by nonhumans" (Latour, 1999:212).

By regarding scientific work as a network-building process between heterogeneous human and nonhuman elements or "actants", the applied approach makes it possible to include as many relevant elements as possible into the analysis (Bingham and Thrift, 2000; Latour, 1996, 2005; Law and Hassard, 1999). On the one hand, travelling scientists are attracted to other places by access to certain research infrastructure and research objects. These comprise all sorts of sociomaterial elements which actor-network theory has conventionally designated as "actants". On the other hand, the scientists are embedded in different social relations, which also influence their decision to become internationally mobile (e.g., organisational aspects, family background, and friendship). While these social relations are often considered as external social context in other approaches, the applied actor-network based approach considers all influencing intellectual, social and material factors, arguing that the motivations for and outcomes of academic mobility are relational effects of the interplay of all relevant "actants". On the individual level, for example, it is possible, as I have done elsewhere (Jöns, 2003a:86-91, 280-281, 356-357), to display individual motivations and results in the form of heterogeneous "chains of associations" (Latour 1987:202-205; Latour 1999:124-125). These "chains of associations" list all identified "actants" next to each other, arguing that it cannot be decided which "actant" would have been most important as it is the whole actor-network that is considered to be responsible for academic mobility and its results. While the findings of the quantitative survey discussed in this paper cannot be displayed in this individualised way, the varying frequencies of responses to certain categories used in the questionnaire indicate which motivations and outcomes were typical, for example, in different academic fields. Based on this understanding, it is also possible to regard the global patterns of academic mobility, which are discussed in the first empirical section of the paper, as the result of a complex network of individual actor-networks and "chains of associations". 


\subsection{Methodological considerations}

Using an actor-network based approach for analysing scientific practice and interaction has at least two important methodological consequences. First, empirical research should be unbiased in regard to predefined categories. Second, the analysis should account for as many influencing factors as possible without stating a priori which realms are more important than others (e.g., human/nonhuman, scientific/social context). These requirements favour the openness of qualitative research methods, so that it is necessary to outline how this paper combines actor-network theory with quantitative methods: The quantitative approach makes it possible to identify typical characteristics of actornetworks by quantifying their meaning; for example, in regard to motivations for academic mobility. While this requires the definition of pre-defined categories in a questionnaire design, the categories applied in this survey were constructed out of the rich qualitative data generated in a previous project (Jöns, 2003a). Therefore, the applied categories can be regarded as the result of following network-building processes without many previous assumptions. In my understanding, actor-network theory does not reject predefined categories per se but tries to provide a framework for understanding how these categories were constructed. Being aware of this heuristic quality of categories and by constructing categories out of individual experiences, the combination of quantitative analysis and actor-network theory helps to reveal common and different features of scientific practices (see Jöns, 2003a:69-75). While some parts of the analysis build on the rather traditional distinction between the natural and technical sciences as well as the arts and humanities (including the social sciences), the argument of the paper is that this distinction is less useful for understanding the geographies of different scientific practices than the differentiation between empirical, experimental, theoretical and argumentative-interpretative work. However, analysing the empirical data confirmed significant variations along the traditional disciplinary categories that also help to inform policy debates, which often deal with these classifications when designing mobility programmes and distributing funding.

This paper subscribes to an explorative quantitative approach, which is based on the idea of grounded theories as outlined by Glaser and Strauss (1967). The aim of this approach is to start with open research questions and to generate hypotheses out of the empirical material rather than to test hypotheses as prescribed by a rigid quantitative research paradigm. Grounded theorising is also often related to qualitative methods, but Glaser and Strauss argued that it can also involve quantitative methods, thereby resolving the apparent contradiction between (a) open research questions and the generation of theory, and (b) the application of quantitative analysis:

"[T]here is no fundamental clash between the purposes and capacities of qualitative and quantitative methods or data. What clash there is concerns the primacy of emphasis on verification or generation of theory - to which heated discussions on qualitative versus quantitative data have been linked historically. [...] Although the emphasis on qualitative data is strong in our book, most chapters also can be used by those who wish to generate theory with quantitative data, since the process of generating theory is independent of the kind of data used" (Glaser and Strauss, 1967, 17-19).

Building upon these methodological considerations, the paper is structured in five parts. A brief review of the relevant literature, linking empirical work and conceptual considerations to ongoing debates about academic mobility and the geographies of science, is followed by three empirical sections that examine key aspects of academic mobility to Germany in the period 1981 to 2000: first, global patterns of interaction, second, motivations to work in Germany for a limited period of time and, third, resulting publications and collaborations. While the empirical sections provide insights into the highly complex circumstances of academic mobility and collaboration, my particular interest in the fifth part of the paper is to examine the ways in which the nature of the research work influenced different cultures of academic mobility and collaboration. This focus on a particular aspect of the wider actor-networks aims to describe the ways in which geography, in the form of varying spatial relations of different research practices, shaped both the motivations for academic mobility and resulting collaborative patterns. However, this is not to say that varying spatial relations of different research practices represent the only aspects that mattered; it rather highlights a set of particular important circumstances that were revealed by the statistical analyses. By proposing a three-dimensional conceptual matrix that accounts for varying degrees of materiality, standardisation and abstraction of different research practices, the paper finally aims to explain typical patterns of academic mobility and collaboration in different fields and types of research work and to contribute to recent theoretical debates on the relationship between knowledge and space (see, e.g., Meusburger, 2000; Harvey, 2005).

\section{Academic mobility and the geographies of science}

Recent work in science studies and geography has focused on historical and geographical variations in the production and dissemination of scientific knowledge (Ophir and Shapin, 1991; Shapin, 1995; Smith and Agar, 1998; Livingstone, 1995, 2000, 2002a, 2003; Naylor, 2005). An important impetus for this work stems from Kuhn's (1962) seminal book, in which he pointed out that scientific methods, concepts, problems and problem solutions are not universally true but always related to shared paradigms that vary over time. More than twenty years later, Latour (1987) and Haraway (1988) argued for the spatially situated character of scientific practice by rejecting the idea of a universal scientific objectivity 
existing independently of local circumstances. According to Latour (1987:247-250), the existence of scientific facts and artefacts in time and space requires the extension of those networks that originally gave birth to them. Wissenschaft thus resembles a network of interconnected nodes in which disproportional amounts of heterogeneous resources are concentrated, transformed and transferred back and forth (Latour, 1987:179-180).

Stimulated by these ideas and by an interest in the history of geography itself, Livingstone (1995, 2000, 2002a, 2003) outlined the foundations and aims of what might be called a "geography of science". He suggested that "a spatial taxonomy of scientific knowledge" could be centred around three main lines of inquiry, namely the analysis of (a) places of knowledge production, (b) sites of consumption, and (c) geographical biography (Livingstone, 2002b). By providing ample historical evidence for the fact that " $[t]$ he growth of scientific knowledge has been intimately bound up with geographical movement", Livingstone (2003:177) reinforces Gregory's (2000:317) reminder that "the connection between cultures of travel and spatial formations of knowledge is an ancient [and intimate] one". But how do these "spaces-inmotion" (Gregory, 2000:317) unfold in the context of contemporary research practice? If the connection is indeed an intimate one, I suggest that the spatial relations of scientific practice and interaction help to explain typical patterns of academic mobility and collaboration in different fields and types of research work.

Despite the praised importance of academic mobility for science and society, surprisingly little is known about global patterns of interaction, motivations for and outcomes of the related transnational movements (Findlay, 1996; Goodwin, 1996; Teichler, 1996; Windham, 1996; Koser and Salt, 1997; Salt, 1997; Iredale and Appleyard, 2001; King, 2002; Ackers, 2005; Barnett and Phipps, 2005). Mainly a question of data availability, most studies on the wider topic concentrate on student rather than staff mobility (Barnett and $\mathrm{Wu}$, 1995; Jallade, 1996; Li et al., 1996; Teichler 2002; Budke, 2003; King and Ruiz-Gelices, 2003; Baláz and Williams, 2004). Only few studies examine the mobility of scientists and scholars (Ackers, 2005; Ackers and Gill, 2005; Heffernan, 1994; Jöns, 2003a; Jöns and Meusburger, 2005; Enders and Teichler, 2005; Morano-Foadi, 2005; Van de Sande et al., 2005; Jöns, 2007) and related networks of communication and collaboration (Button et al., 1993; Ekmann and Quandt, 1999). In the context of scientific migration, research has focused on questions of "brain drain" and "brain gain", even if "brain circulation" begins to receive more attention (for recent reviews, see Ackers, 2005; Jalowiecki and Gorzelak, 2004; Pethe, 2006). Along these lines, King (2002:89-90) argued that geographical movements of the highly skilled are characterised by "new space-time flexibilities" that complicate the "never straightforward boundary between migration and mobility".
A growing number of studies apply a comparative approach to science by examining cultures of academic work, international contacts and scientific career trajectories in different geographical and disciplinary contexts (Becher, 1989; Crawford et al., 1993; Wagner, 2005; Ackers and Gill, 2005; Laudel, 2005; Morano-Foadi, 2005; Jöns, 2007; Taylor et al., 2007). While the arts and humanities are rarely included in these studies, the main challenge regarding research on academic mobility and the geographies of science seems to lie in linking three research traditions:

1. empirical work on academic mobility that needs a better "theoretical basis of analysis" (Teichler, 1996:339; see also Iredale, 2001:7);

2. historical studies on the meaning of geography in the making of science (e.g., Livingstone, 2003);

3. conceptual accounts of academic travel and scientific work, which require more detailed empirical case studies (Latour, 1999:viii; Jöns, 2003a:16-17; Barnett and Phipps, 2005:3-4).

Striving for the establishment of such a linkage, the focus of this paper is on the mobility of academics, who went to Germany in the period 1981 to 2000 in order to pursue a specific research project at one or more host institutions for about a year. Since $80 \%$ of the visiting researchers returned to their country of origin afterwards (10\% moved on to another country and $8 \%$ stayed in Germany; $2 \%$ no response), the Humboldt fellowship programme typically sponsors circular transnational mobility. Among the questions raised by these movements, the following will be examined in this paper:

- Where did the visiting Humboldt research fellows come from?

- Why did they choose to spend their research stay in Germany?

- Could they have done their research project also at home or in any other country?

- To what extent did the visiting researchers write joint publications with colleagues in Germany as a result of their stay?

Based on the rich data of the postal survey, the paper presents empirical insights into the nature of academic mobility and collaboration in the late $20^{\text {th }}$ century and offers a conceptual explanation of typical mobility and collaborative cultures in different disciplines and types of research work. 


\section{Global patterns}

Germany's post-war history of international academic relations has been shaped by the Humboldt fellowship programme, which was established by the Alexander von Humboldt Foundation in 1953 (Jansen, 2004). Humboldt research fellowships have allowed highly-qualified foreign scholars with a doctoral degree and below 40 years of age to carry out a research project in the Federal Republic. With more than 50000 applicants and 20000 research fellows from more than 130 countries in the first five decades of its existence, the Humboldt fellowship programme has been the largest sponsorship programme for long-term research stays at German institutions of higher education and research (Jöns, 2002). Academics from all countries and disciplines have been encouraged to apply for the research fellowships. Thus, each application can be interpreted as a result of professional and personal interests mediated by the opportunities and restrictions of a specific place of work at a certain time. The selection of Humboldt research fellows, resulting in an average success rate of $34 \%$, has been based on the candidate's academic qualification and assessed in the context of the general research situation in the applicant's country of origin. There have been no pre-determined quotas or priorities with regard to nationality or discipline, which provides a unique opportunity for examining transnational mobility and collaboration in different countries and academic fields. ${ }^{2}$ Due to the open application and selection processes, the research projects conducted by Humboldt research fellows have seemed to be less influenced by policy interests of the funding institution than those funded by other bodies such as the European Union. Mobility programmes funded by the European Union usually restrict the country of origin to member states and often set priorities in regard to disciplines and research topics. Therefore, transnational mobility in the Humboldt framework seems to be particularly well suited for comparing how the nature of research work influences motivations and outcomes of academic mobility.

A continuous growth in the number of applications, granted fellowships and countries of origin from 1954 to the early 1980s reflects a gradual reintegration of Germany into the international scientific community after World War Two. It also mirrors the expansion of the German tertiary educational system in the 1970s and a substantive increase in the quality of research and teaching in German higher education. Rising qualifications of Humboldt research fellows and a growing interest in the programme by applicants from the USA indicate that the process of reintegration had been successfully pursued in most disciplines by the late 1970s (Jöns,

\footnotetext{
${ }^{2}$ Humboldt research fellows of the period 1981 to 2000 were on average 35.8 years old, only $12.6 \%$ were female. The length of their main Humboldt stay was 11 months on average. About $80 \%$ of them worked at universities. Other important host institutions included Max Planck Institutes and major state-subsidised research institutions (e.g., DESY, GSI).
}

2003b). The number of applications for Humboldt research fellowships in $1980(\mathrm{~N}=1481)$ was only surpassed in 1988 $(\mathrm{N}=1536)$, when the impending end of the Cold War led to enormous changes in the network of international academic relations. While the number of applications from Poland had already doubled in the period 1980 to 1989 , the late $1980 \mathrm{~s}$ and early 1990s saw a boom in applications from all successor states of the Soviet Union and the former COMECON countries of Central and South Eastern Europe. Consequently, the number of applications for Humboldt research fellowships reached its maximum in 1990 to 1992, when the number of applications exceeded 1900 per year. $^{3}$

During the 1990s, the total number of applications per year dropped to levels only slightly above those of the 1980s. In the year 2000, it even fell below 1200 applications, which can be explained by a complex bundle of developments in Germany and abroad: There was an exceptionally strong interest in Germany during the unique historical situation of unification, while international scientific contacts diversified after the fall of the Iron Curtain (Wagner and Leydesdorff, 2005a). This went hand in hand with a growing international competition for highly qualified visiting researchers and a considerable rise in the range of fellowships on offer world-wide. The consequences of the drop in the birth-rate in highly-developed industrialised nations meant that there were fewer young academics available, while in many countries graduates preferred financially more attractive jobs in industry to those in academia. In the USA, the competition among post-docs for jobs in academia became so high that many of them had to be present in the job market for interviews and could not afford to leave the country for one or two years. ${ }^{4}$ In Poland and Hungary, the increasing predominance of Anglo-American scientific discourses led to a re-orientation from an initial focus on Germany to a growing interest in the UK and the USA. Since cultural and biographical bonds to the host country were of particular importance for the decision to spend a long-term research stay abroad, world-wide diminishing biographical connections to Germany and Central Europe can also be held responsible for the further decrease in the number of visiting researchers during the late 1990s (Jöns, 2003a:193-198, 2005:12-14). Finally, investment in large research facilities, characterising German science in the 1980s, stagnated in the first half of the 1990s, when restructuring efforts of higher education

\footnotetext{
${ }^{3}$ The boom in applications varied among different countries with regard to period of time, extent, and duration (e.g., Hungary: 19871992, Poland: 1988-1989, former Czechoslovakia: 1989-1992, Romania: 1991-1992). In Romania and former Czechoslovakia, the post-1989 euphoria for academic travel to Germany was less strong than during the reform movements in the late 1960s and early 1970s (Jöns, 2003b).

${ }^{4}$ This situation is reinforced by the fact that the symbolic meaning of post-doctoral positions in the USA, specifically at the large research universities, is often valued much higher than work experience in Europe.
} 
and research in the new Länder became a priority (Weingart, 1998:727-731).

In the 1980s, the focal point of sponsorship lay on the USA, Poland and Japan with more than 400 research fellows from each country (34\% of all Humboldt research fellows). The 1990s, however, saw a huge increase in applications and fellowships from China and Russia, the USA being the third country with more than 400 research fellows (32\% of all Humboldt research fellows). The considerable interest of qualified visiting researchers from Asia and the USA as well as from Western and Eastern Europe underlines Germany's mediating position at the upper levels of a worldwide ranking of national research contexts (Fig. 1). The geographical pattern of applications for Humboldt research fellowships in the period 1996 to 2000 underlines a strong interest in German higher education and research from China, India and Russia. It also reveals distinct transnational spaces of knowledge production in the natural sciences, the engineering sciences, and the arts and humanities (Fig. 2): The interest in the natural sciences was widespread, though 54\% of all applications came from six countries (India: 17.3\%, China: $16.5 \%$, Russia: $8 \%$, Japan, France and USA: 4\% each). In engineering, $68 \%$ of all applications were concentrated in only seven countries (China: $31 \%$, India: $18 \%$, Russia: 7\%, USA, Japan, Turkey and Ukraine: $3 \%$ each), while the interest in the arts and humanities was least concentrated in individual countries; $42 \%$ of all applications came from six countries (USA: 14\%, Russia: 9\%, Italy: 7\%, Poland: 5\%, Japan and Great Britain: $4 \%$ each). While transnational mobility to Germany in the natural and technical sciences was thus dominated by scientists from Asia, interest in Germany from the arts and humanities was largest from the USA and also much stronger from within Europe. These asymmetrical global patterns of academic exchange in different scientific fields are the result of variations in international politics, socio-economic development, historical and cultural relations, national research traditions and political priorities as well as technological and intellectual standards and prestige. ${ }^{5}$ They also imply different cultures of academic mobility and collaboration by discipline, which will be further examined in the course of this paper.

\section{Motivations}

The motivations for spending a year of research in Germany represent a complex bundle of influencing factors. These dif-

\footnotetext{
${ }^{5}$ The latter are expressed in different success rates by country of origin. Among the 20 countries with most applications, the success rates ranged from more than every second in the case of applications from Canada (55\%), Australia (52\%) and Great Britain (51\%) to less than one third (China: 33\%, Nigeria: 32\%, Bulgaria: $31 \%$, Ukraine: $28 \%$, Turkey: $28 \%$, India: $21 \%$, Egypt: $16 \%$ ). The success rate was highest in the arts and humanities (35\%), followed by the natural sciences $(31 \%)$ and engineering $(28 \%)$.
}

fer only slightly from motivations for scientific migration in terms of less emphasis on economic issues and more emphasis on new scientific and cultural experiences and contacts (Department of Trade and Industry, 2002; Martin-Rovet, 2003). More than $80 \%$ of the Humboldt research fellows were motivated by particular research projects, contents and infrastructures, which underlines their specific scientific interest in Germany as a place of research (81.3\%). More than two thirds of the visiting researchers were attracted by existing academic contacts, particularly with their academic host $(68.3 \%)$, while more than a fourth had personal relations through family and friends (27.5). ${ }^{6}$ The most frequent motivations, named by more than every second Humboldt research fellow, also included general reasons for a sabbatical abroad such as the search for new experiences and ideas $(75.4 \%)$, time to do research and to publish academic work $(66.8 \%)$ and contacts with foreign researchers $(55.1 \%)$. Academic motivations related to Germany more specifically were headed by the prestige of the Humboldt Foundation $(67.0 \%)$, a particular research project or subject $(62.1 \%)$ and the scientific reputation of the host institution (56.2\%). Also more than every second Humboldt research fellow in the period 1981 to 2000 stated that a cultural and historical interest in Germany influenced his or her decision to apply for the fellowship (55.5\%), which highlights the importance of keeping the interest in Germany alive through presence in the media, school exchanges and cultural activities offered by the Goethe Institute and other non-profit organisations.

\subsection{Regional differences}

The responses of researchers from different countries expose some of the ways in which national research contexts provide different settings for academic work and mobility (Table 1). They reveal that cultural and geographical proximity and distance continue to shape international academic exchange and enable the identification of different national academic cultures around the globe that are also influenced by large socio-economic disparities. Specific research projects in Germany attracted most Humboldt fellows from the global centres of scientific learning in the USA, Canada and Australia. Every second researcher from the USA and Canada, more than in any other region, had maintained good contacts with his or her academic host before the research stay in Germany, wanted to improve his or her German language ability and had a cultural and historical interest in the country. This might be related to the strong representation of the arts and humanities among visiting researchers from these countries. Also, most Humboldt fellows who had friends, relatives or

\footnotetext{
${ }^{6}$ The questionnaire contained 36 motivations in three sections: 1) Research in Germany and the host institution (15 items), 2) Biographical and cultural relations (9 items), 3) Personal situation (12 items). The three categories named in this comparison are combinations from section one (research/academic contacts) and two (personal relations).
} 


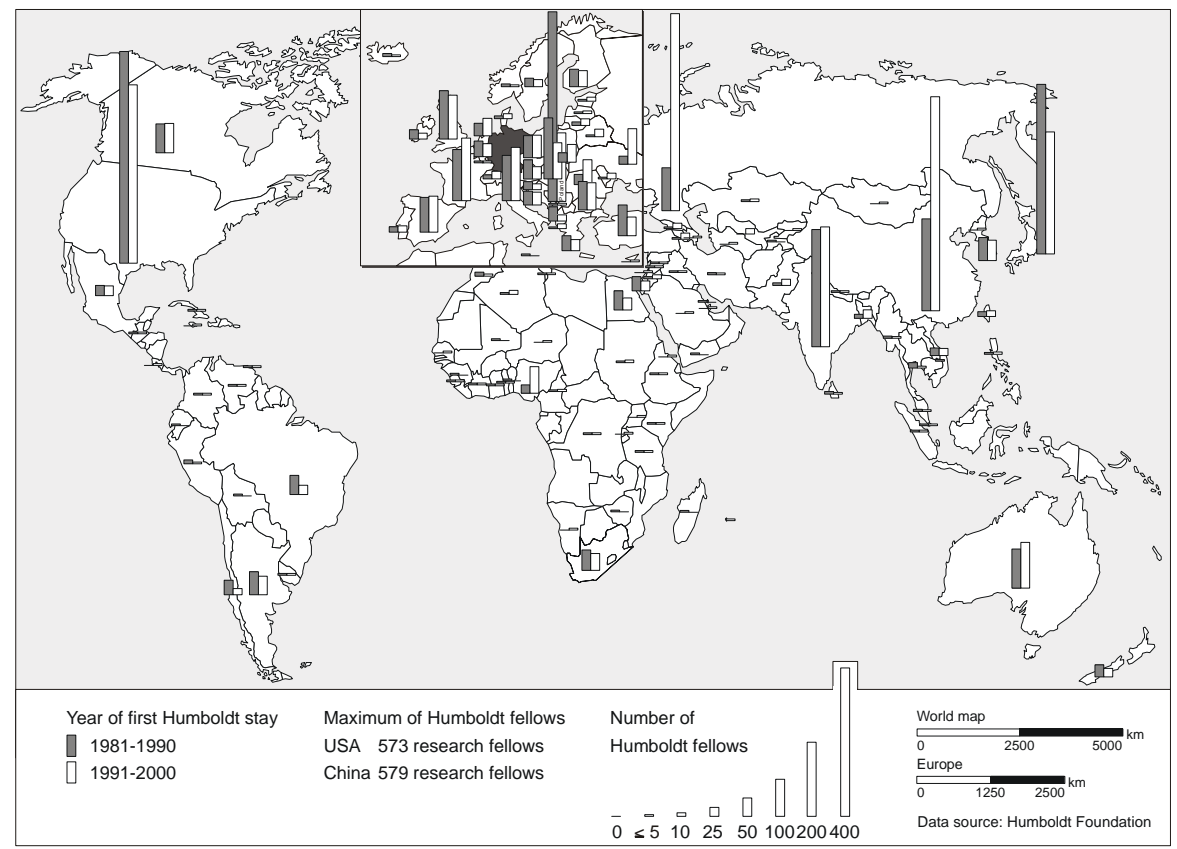

Fig. 1. Countries of origin of Humboldt research fellows in the 1980s and 1990s.

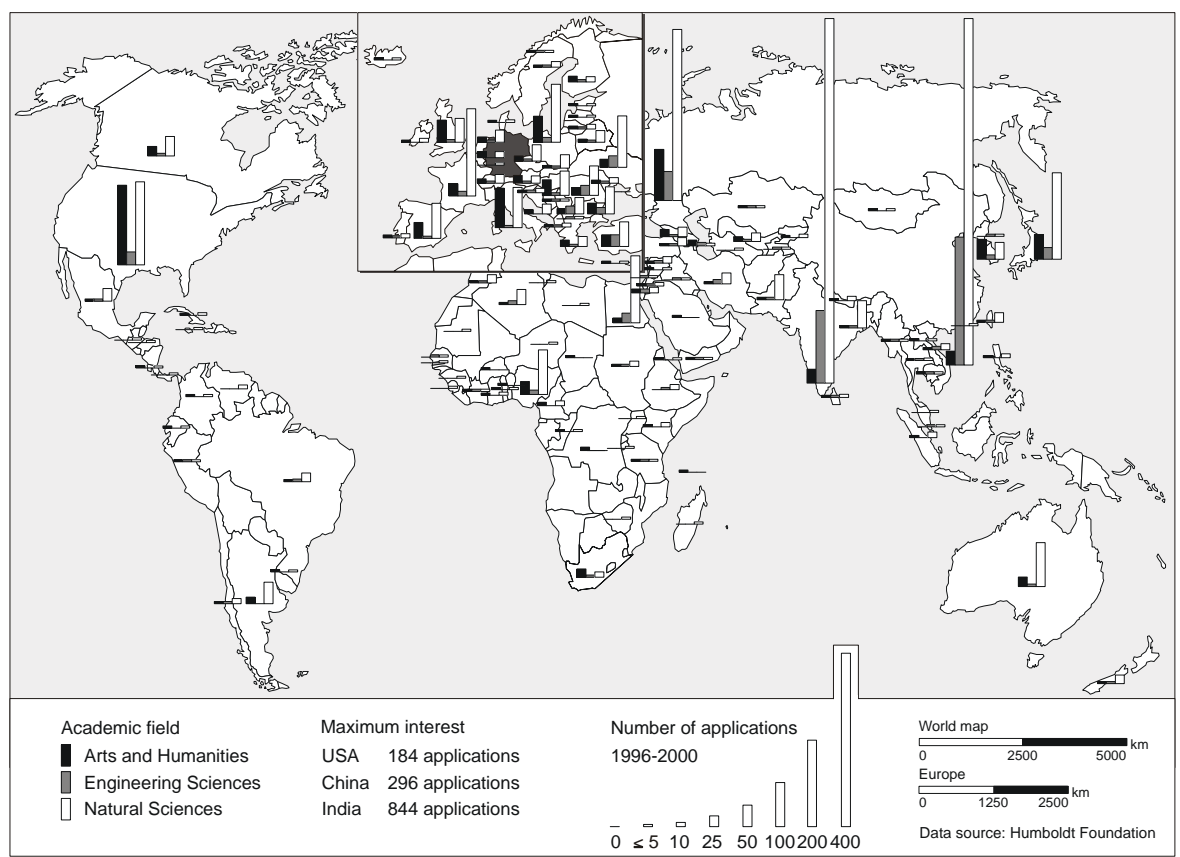

Fig. 2. Countries of origin of applications for Humboldt research fellowships, 1996-2000.

family roots in Germany and biographical connections to Central Europe came from the USA and Canada, which underlines close historical and cultural transatlantic relations. These might further decline in the future for historical reasons and thus would have to be ensured through active engagement by individuals and institutions.
When asked about their motivation to spend a Humboldt research stay in Germany, a particularly high percentage of visiting researchers from South Asia, South East Europe and Central and South America named the high prestige of the Humboldt Foundation. Humboldt fellows from South Asia and South Eastern Europe were also often motivated by the 
Table 1. Motivations for a Humboldt research stay in Germany by region of origin, 1981-2000 (in \%; own survey, 2003, n=1131).

\begin{tabular}{|c|c|c|c|c|c|c|c|c|c|c|c|c|c|c|c|}
\hline Item & Topic & SIG & TOT & USA & CSA & AFR & EU & SEE & ECE & FSU & MEC & SAS & SEA & EAS & AUS \\
\hline $1 \mathrm{a}$ & Particular research projects & $* * *$ & 62.1 & 78.9 & 68.9 & 53.2 & 68.0 & 59.7 & 59.4 & 56.2 & 63.2 & 57.3 & 76.9 & 51.7 & 73.5 \\
\hline $1 \mathrm{~b}$ & International projects & $* *$ & 8.7 & 9.9 & 13.3 & 10.6 & 9.3 & 11.3 & 3.0 & 10.0 & 26.3 & 12.5 & 0.0 & 5.1 & 17.6 \\
\hline $1 \mathrm{~d}$ & Specific research infrastructure & $* * *$ & 34.9 & 30.3 & 28.9 & 42.6 & 39.0 & 48.4 & 42.4 & 50.0 & 36.8 & 30.2 & 30.8 & 15.9 & 14.7 \\
\hline 1f & Good experience with collaboration & $* * *$ & 15.8 & 16.9 & 17.8 & 25.5 & 18.6 & 17.7 & 20.6 & 17.7 & 36.8 & 3.1 & 23.1 & 8.0 & 8.8 \\
\hline $1 \mathrm{~g}$ & Scientific reputation of host institution & $*$ & 56.2 & 56.3 & 60.0 & 51.1 & 58.7 & 74.2 & 61.2 & 50.8 & 42.1 & 62.5 & 61.5 & 46.6 & 52.9 \\
\hline $1 \mathrm{~h}$ & Good contacts with academic host & $* * *$ & 38.0 & 54.9 & 42.2 & 40.4 & 45.9 & 30.6 & 37.0 & 32.3 & 47.4 & 21.9 & 23.1 & 33.5 & 35.3 \\
\hline $1 \mathrm{j}$ & Good contacts with his or her students & $*$ & 11.3 & 15.5 & 13.3 & 19.1 & 15.1 & 12.9 & 12.7 & 9.2 & 21.1 & 8.3 & 0.0 & 4.0 & 8.8 \\
\hline $1 \mathrm{n}$ & Interest of academic host & ** & 33.8 & 40.1 & 22.2 & 36.2 & 34.9 & 32.3 & 24.2 & 33.8 & 31.6 & 51.0 & 30.8 & 31.8 & 38.2 \\
\hline 10 & Financial attractiveness of fellowship & $* * *$ & 42.6 & 50.0 & 31.1 & 34.0 & 39.5 & 46.8 & 53.3 & 61.5 & 36.8 & 18.8 & 30.8 & 36.4 & 38.2 \\
\hline $1 \mathrm{p}$ & Prestige of the Humboldt Foundation & $* * *$ & 67.0 & 66.2 & 82.2 & 61.7 & 65.7 & 82.3 & 70.3 & 72.3 & 52.6 & 85.4 & 53.8 & 48.3 & 61.8 \\
\hline $2 \mathrm{a}$ & Friends or relatives living in Germany & $* * *$ & 15.7 & 25.4 & 15.6 & 12.8 & 20.9 & 16.1 & 18.2 & 10.0 & 10.5 & 4.2 & 7.7 & 10.8 & 11.8 \\
\hline $2 b$ & Family roots in Germany & $* * *$ & 7.2 & 24.6 & 11.1 & 4.3 & 3.5 & 4.8 & 9.1 & 3.8 & 15.8 & 2.1 & 7.7 & 0.6 & 2.9 \\
\hline $2 \mathrm{c}$ & Partner has German roots & $* * *$ & 4.0 & 11.3 & 2.2 & 2.1 & 8.1 & 1.6 & 1.2 & 1.5 & 5.3 & 1.0 & 7.7 & 1.1 & 8.8 \\
\hline $2 d$ & Biographical connection to Central Eu. & $*$ & 3.4 & 8.5 & 6.7 & 2.1 & 2.9 & 4.8 & 4.8 & 1.5 & 0.0 & 2.1 & 0.0 & 0.6 & 2.9 \\
\hline $2 \mathrm{f}$ & Cultural \& historical interest & $* * *$ & 55.5 & 65.5 & 57.8 & 31.9 & 49.4 & 64.5 & 54.5 & 60.0 & 42.1 & 50.0 & 15.4 & 63.1 & 50.0 \\
\hline $2 \mathrm{~h}$ & Good experience with previous stays & $* * *$ & 30.5 & 38.0 & 31.1 & 40.4 & 37.8 & 27.4 & 33.9 & 30.8 & 47.4 & 15.6 & 30.8 & 18.2 & 29.4 \\
\hline $2 \mathrm{j}$ & Short distance from country of origin & *** & 10.5 & 2.1 & 0.0 & 4.3 & 19.2 & 21 & 28.5 & 10.8 & 10.5 & 1.0 & 0.0 & 0.6 & 2.9 \\
\hline $3 b$ & Time to do research and publish & $* * *$ & 66.8 & 75.4 & 66.7 & 76.6 & 70.3 & 74.2 & 77.0 & 63.1 & 89.5 & 59.4 & 76.9 & 42.6 & 73.5 \\
\hline $3 \mathrm{~d}$ & Dissemination of research results & $* * *$ & 21.7 & 19.0 & 24.4 & 25.5 & 15.7 & 37.1 & 29.1 & 32.3 & 47.4 & 24.0 & 7.7 & 8.0 & 5.9 \\
\hline $3 \mathrm{e}$ & Improvement of German & $* * *$ & 39.5 & 57.0 & 28.9 & 31.9 & 36.6 & 54.8 & 54.5 & 45.4 & 42.1 & 30.2 & 0.0 & 16.5 & 38.2 \\
\hline $3 \mathrm{f}$ & Improvement in career opportunities & $* * *$ & 49.3 & 40.8 & 48.9 & 55.3 & 56.4 & 59.7 & 44.2 & 41.5 & 42.1 & 66.7 & 30.8 & 42.6 & 64.7 \\
\hline $3 \mathrm{~g}$ & Gathering of foreign experience & $* * *$ & 47.6 & 54.2 & 26.7 & 53.2 & 43.0 & 56.5 & 45.5 & 55.4 & 36.8 & 53.1 & 30.8 & 43.2 & 67.6 \\
\hline $3 \mathrm{~h}$ & Few job opportunities in home country & $* * *$ & 8.4 & 2.8 & 11.1 & 12.8 & 22.7 & 8.1 & 2.4 & 16.9 & 0.0 & 4.2 & 0.0 & 1.7 & 5.9 \\
\hline \multirow[t]{2}{*}{$3 \mathrm{j}$} & Lack of research funds & $* * *$ & 16.5 & 4.2 & 8.9 & 31.9 & 11.0 & 46.8 & 15.8 & 46.2 & 26.3 & 9.4 & 7.7 & 4.0 & 5.9 \\
\hline & Number of respondents & & 1128 & 142 & 45 & 47 & 172 & 62 & 165 & 130 & 19 & 96 & 13 & 176 & 34 \\
\hline
\end{tabular}

Abbreviations: Statistical SIGnificance; TOTal; USA and Kanada; Central and South America (incl. Mexico); AFRica; EU-15; South East Europe; East Central Europe; Former Soviet Union and successor states; Middle Eastern Countries; South ASia; South East Asia; East ASia; AUStralia and Oceania; the figures for the category "Other European countries" are not displayed.

prospect of better career opportunities through the Humboldt fellowship. In addition to fellows from the USA, the interest in German language was particularly high among visiting researchers from South Eastern and East Central Europe, while the access to specific research infrastructure was mentioned most often by Humboldt fellows from the former Soviet Union, from South Eastern Europe, East Central Europe and Africa. In support of other studies, an important motivating factor for a research stay within the European Union was a "lack of employment opportunities in the home country" (Morano-Foadi, 2005:148). The number of Humboldt fellows from the European Union (EU-15), who mentioned this aspect (22.7\%), was even higher than among Humboldt fellows from the former Soviet Union and its successor states (16.9\%). However, for almost every second visiting researcher from the former Soviet Union and its successor states, the decision to apply for a Humboldt research fellowship was influenced by a lack of research funds (46.2\%; all regions: $16.5 \%$ ). Accordingly, every second Russian Humboldt fellow was interested in specific research infrastructure and appreciated the financial attractiveness of the Humboldt fellowship.

\subsection{Subject-specific circumstances}

During the post-war period, the disciplinary profile of visiting researchers to Germany has significantly shifted from an emphasis on the arts and humanities to a focus on the natural and technical sciences. This process has been based on a growing economic importance and a targeted development of scientific and engineering research at German institutions of higher education and research since the late 1960s and is related to subject-specific cultures of academic mobility and collaboration. While the establishment of new research infrastructure in the physical, biological and technical sciences massively strengthened scientific interest in Germany, the mobilisation of new visiting researchers in the arts and humanities remains difficult as language skills and cultural knowledge are often necessary for conducting research projects in these fields and the number of foreign scholars with German language skills is not only restricted but has recently been declining for historical reasons. Therefore, the shift in subject emphasis among Humboldt research fellows cannot be simply attributed to the international attractiveness of different academic communities in Germany (Fig. 3). It rather indicates that the "expectation of mobility" varies in different fields of academic work (Ackers, 2005:104) and that different research practices require different spatial contexts. 
Table 2. Motivations for a Humboldt research stay in Germany by discipline, 1981-2000 (in \%; own survey, 2003, n=1131).

\begin{tabular}{|c|c|c|c|c|c|c|c|c|c|c|c|c|c|c|c|}
\hline Item & Topic & SIG & TOT & PHY & $\mathrm{CHE}$ & EAR & $\mathrm{BIO}$ & MED & $\begin{array}{l}\text { MAT } \\
\text { COM }\end{array}$ & ENG & $\begin{array}{l}\text { ECO } \\
\text { SOC }\end{array}$ & LAW & HIS & PHI & $\begin{array}{l}\text { LAN } \\
\text { CUL }\end{array}$ \\
\hline $1 \mathrm{a}$ & Particular research projects & $* *$ & 62.1 & 62.1 & 66.3 & 50.0 & 71.0 & 73.2 & 52.6 & 59.2 & 58.3 & 47.4 & 59.1 & 70.6 & 55.7 \\
\hline $1 d$ & Specific research infrastructure & $* * *$ & 34.9 & 30.8 & 27.1 & 40.4 & 29.7 & 18.3 & 23.1 & 27.2 & 33.3 & 52.6 & 63.6 & 52.9 & 54.1 \\
\hline $1 \mathrm{e}$ & Ongoing research collaboration & $*$ & 14.6 & 14.8 & 11.4 & 19.2 & 12.9 & 23.2 & 23.1 & 14.4 & 20.8 & 5.3 & 12.1 & 3.9 & 15.6 \\
\hline $1 \mathrm{~h}$ & Good contacts with academic host & $* * *$ & 38.0 & 31.4 & 27.1 & 55.8 & 34.8 & 42.7 & 39.7 & 34.4 & 45.8 & 39.5 & 43.9 & 43.1 & 50.8 \\
\hline $1 \mathrm{k}$ & Other good academic contacts & $* * *$ & 10.8 & 6.5 & 7.2 & 7.7 & 3.2 & 12.2 & 14.1 & 8.0 & 16.7 & 10.5 & 18.2 & 17.6 & 24.6 \\
\hline 11 & German contacts of (former) mentor & $*$ & 15.6 & 16.0 & 10.2 & 11.5 & 14.2 & 14.6 & 23.1 & 16.0 & 16.7 & 34.2 & 12.1 & 11.8 & 18.9 \\
\hline $2 \mathrm{a}$ & Friends or relatives living in Germany & $* * *$ & 15.7 & 11.2 & 12.0 & 25.0 & 12.3 & 24.4 & 11.5 & 11.2 & 33.3 & 10.5 & 16.7 & 25.5 & 22.1 \\
\hline $2 b$ & Family roots in Germany & $*$ & 7.2 & 3.6 & 4.8 & 11.5 & 9.0 & 9.8 & 6.4 & 4.0 & 16.7 & 2.6 & 7.6 & 5.9 & 13.1 \\
\hline $2 f$ & Cultural \& historical interest & $* * *$ & 55.5 & 46.7 & 50.6 & 55.8 & 49.0 & 63.4 & 51.3 & 54.4 & 50.0 & 57.9 & 71.2 & 72.5 & 65.6 \\
\hline $2 \mathrm{~h}$ & Good experience with previous stays & $* * *$ & 30.5 & 21.9 & 21.7 & 30.8 & 21.3 & 31.7 & 25.6 & 27.2 & 45.8 & 39.5 & 42.4 & 51.0 & 50.8 \\
\hline $2 \mathrm{j}$ & Short distance from country of origin & $*$ & 10.5 & 16.0 & 7.2 & 11.5 & 9.0 & 13.4 & 19.2 & 12.0 & 12.5 & 5.3 & 4.5 & 3.9 & 7.4 \\
\hline $3 a$ & Search for new academic experience & $* * *$ & 75.4 & 76.9 & 79.5 & 80.8 & 80.6 & 75.6 & 70.5 & 78.4 & 70.8 & 86.8 & 50.0 & 64.7 & 73.8 \\
\hline $3 b$ & Time to do research \& publish & $* * *$ & 66.8 & 58.6 & 52.4 & 65.4 & 63.2 & 65.9 & 70.5 & 60.8 & 87.5 & 63.2 & 81.8 & 86.3 & 87.7 \\
\hline $3 c$ & Contacts with foreign researchers & $*$ & 55.1 & 55.0 & 53.6 & 61.5 & 46.5 & 41.5 & 57.7 & 66.4 & 54.2 & 60.5 & 56.1 & 52.9 & 59.8 \\
\hline $3 d$ & Dissemination of research results & $* * *$ & 21.7 & 18.3 & 10.8 & 34.6 & 18.7 & 15.9 & 23.1 & 24.8 & 16.7 & 21.1 & 36.4 & 27.5 & 30.3 \\
\hline $3 e$ & Improvement of German & $* * *$ & 39.5 & 30.8 & 31.3 & 48.1 & 34.8 & 36.6 & 38.5 & 38.4 & 41.7 & 71.1 & 39.4 & 51.0 & 53.3 \\
\hline $3 f$ & Improvement in career opportunities & $* * *$ & 49.3 & 47.3 & 60.2 & 50.0 & 58.1 & 56.1 & 43.6 & 50.4 & 45.8 & 42.1 & 31.8 & 35.3 & 41.8 \\
\hline $3 g$ & Gathering of foreign experience & $* *$ & 47.6 & 49.7 & 53 & 50.0 & 50.3 & 52.4 & 50 & 56.8 & 33.3 & 39.5 & 31.8 & 33.3 & 38.5 \\
\hline 31 & Distance from everyday life & $* * *$ & 7.8 & 1.8 & 7.8 & 13.5 & 2.6 & 4.9 & 14.1 & 4.8 & 8.3 & 13.2 & 16.7 & 9.8 & 13.9 \\
\hline \multirow[t]{2}{*}{$3 \mathrm{~m}$} & Private reorientation & $*$ & 4.8 & 1.2 & 4.2 & 11.5 & 5.8 & 11.0 & 3.8 & 3.2 & 4.2 & 2.6 & 0.0 & 5.9 & 7.4 \\
\hline & Number of respondents & & 1128 & 169 & 166 & 52 & 155 & 82 & 78 & 125 & 24 & 38 & 66 & 51 & 122 \\
\hline
\end{tabular}

Abbreviations: Statistical SIGnificance; TOTal; PHYsics; CHEmistry; EARth Sciences; BIO Sciences; MEDicine; MAThematics \& COMputer Sciences; ENGineering Sciences; ECOonomic \& SOCial Sciences; LAW Studies; HIStorical Sciences; PHIlosophy; LANguage \& CULtural Studies.

Accordingly, the motivations for a research stay in Germany varied significantly between different academic fields (Table 2). The most striking differences existed between highly place-specific practices in history, philosophy, language and cultural studies and less place-specific practices in physics and chemistry. Among those Humboldt fellows working in highly place-specific academic fields, more than every second named specific research infrastructure, a cultural and historical interest in Germany and good experiences with previous stays as motivating factors; more than three quarters of them enjoyed the time to do research and publish academic work. While all of these figures exceeded the average of all disciplines, the percentage of physicists and chemists considering these aspects as motivating factors lay far below the average. In chemistry, however, most Humboldt fellows, despite their few previous experiences in Germany, were motivated by the possibility of better career opportunities after the Humboldt stay. On the one hand, this points to a high convertibility of chemical knowledge (Ackers, 2005:102); on the other hand, it illustrates the high international reputation of chemical research in Germany.

\subsection{Place-specificity}

For almost every second Humboldt fellow (46.4\%), the contact to his or her academic host developed through their own international academic mobility $(26.8 \%)$, or those of their academic host $(21 \%)$, their supervisor $(7.3 \%)$ or other people $(6.8 \%)$. Further $11.6 \%$ met their academic host at in-

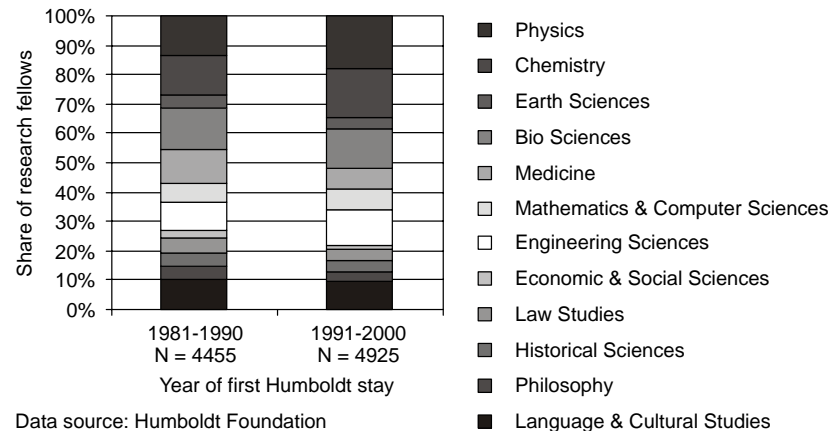

Fig. 3. Humboldt research fellows by academic field, 1980s and 1990s.

ternational conferences or similar events. Personal contact through different forms of academic mobility thus remains pivotal for the generation, maintenance and expansion of international academic relations. This personal contact, the high reputation of the Humboldt Foundation, the financial attractiveness of the Humboldt fellowship and a high quality of research in Germany contributed to attracting a large number of visiting researchers, who could also have done their project at home or in other countries $(69.8 \%)$. Analysing the place-specificity of Humboldt research projects, i.e. the extent to which they were bound to a particular setting in Germany, reveals striking differences between different fields and types of work, while there are less variations between 
(a)

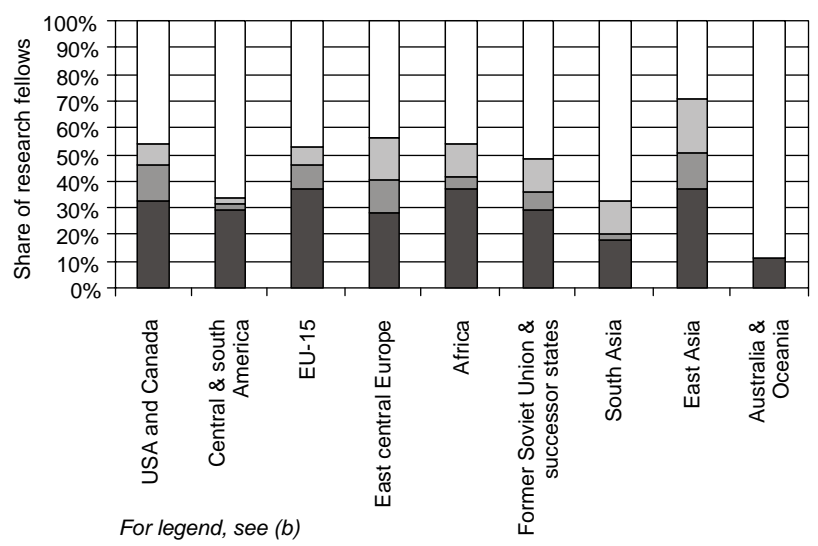

(b)

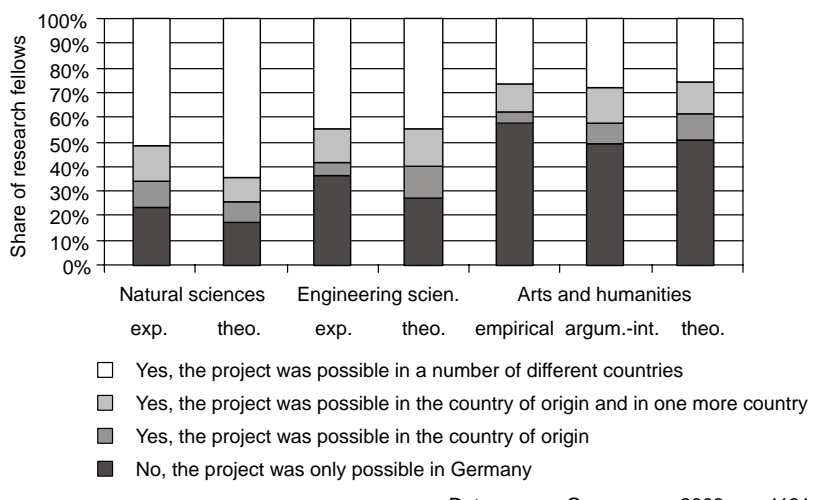

Data source: Own survey, 2003, n = 1131

Fig. 4. Possibility of doing the Humboldt research project in another country than Germany, 1981-2000. (a) By country of origin [statistical significance: ***]. (b) By type of work [statistical significance: $* * *]$.

countries of origin (Fig. 4). Research projects in the arts and humanities, and particularly those that involved empirical work, were most frequently tied to the German context and less frequently also possible in other countries than Germany. They were followed by experimental and theoretical projects in engineering and in the natural sciences. The reasons for this ranking and for the fact that theory in the natural sciences appears to be the most "ubiquitous" subject will be discussed after more characteristics of subject-specific cultures of academic mobility and collaboration have been explored in the next section.

\section{Collaborations}

The analysis so far has shown that academic mobility is structured by a great variety of circumstances, ranging from international politics and socio-economic disparities to cultural affinity, specific research projects and personal contacts. Once the researchers are in Germany, however, it does hardly matter where they came from: Their scientific interaction and the immediate scientific results of their research stays vary considerably according to subject-specific scientific practices and collaborative cultures. This can be illustrated by a comparison of the visiting researchers' collaborations in Germany before and after their Humboldt stay.

\subsection{Previous joint publications}

Joint publications are a particular frequent example of collaborations between visiting researchers and their colleagues (Jöns, 2003a:354, 351-418). Prior to their first Humboldt research stay in Germany, every fifth visiting researcher had published joint work with colleagues in Germany $(22.4 \%)$. Variations between researchers from different countries reveal the significance of geographical, political and cultural proximity for global publishing spaces by creating more opportunities for researchers from European countries to publish with colleagues in Germany than for those in South and East Asia (Fig. 5a-A). However, the share of visiting Humboldt fellows from Australia, who had published with colleagues in Germany prior to their research stay, amounted to $3.7 \%$ in the period 1961 to 1980 (USA and Canada: $13.5 \%$; all countries: $15.9 \%$ ) and rose to $24.4 \%$ in the period 1981 to 2000 (USA and Canada: 24.8\%; all countries: $22.4 \%$ ). This underlines the decreasing importance of spatial proximity for international collaborations and a growing importance of collaborative projects in the natural and technical sciences (Wagner, 2005; Wagner and Leydesdorff, 2005b). Particular high shares of previous joint publications by Humboldt visiting researchers from South West Asia, South East Asia and Africa can be explained by the fact that many of them did their PhD or spent a previous research stay in Germany. Previous academic stays abroad seem both to help and to motivate researchers from developing countries to further participate in international scientific discourses.

\subsection{Resulting joint publications}

As a result of the Humboldt research stay, more than two thirds of all visiting researchers in the period 1981 to 2000 wrote joint publications with their colleagues in Germany (70.7\%). The extent, to which collaborations with colleagues in Germany took place, varied less between researchers from different countries than between researchers working in different fields and with different methods (Fig. 5a-B and 5b-B). Joint publications were most frequently written in physics $(92.3 \%)$, chemistry $(89.8 \%)$, medicine $(87.8 \%)$, engineering $(87.2 \%)$ and the biological sciences $(87.1 \%)$, while research in mathematics and in the earth sciences was characterised by a greater individuality $(65.4 \%$ each). The individuality of the research work was greatest in the arts and humanities with significant variations between different fields. The spectrum ranged from every second economist and social scientist $(50.0 \%)$, who wrote joint publications with colleagues in 
Germany, to roughly one third in language and cultural studies $(32.2 \%)$ and in history (31.1\%), every fifth in law $(21.1 \%)$ and only every sixth in philosophy $(15.7 \%)$.

Significant differences in collaborative cultures can also be observed for different types of research work. The frequency of joint publications with German colleagues ranged from a quarter of Humboldt fellows conducting argumentative and interpretative work in the arts and humanities (25.3\%) to almost all Humboldt fellows working in experimental engineering (97.3\%; Fig. 5b-B). These collaborative cultures in different fields and types of work are so important that they explain variations in resulting joint publications among researchers from different countries of origin (Fig. 5a-B): While two fifth of Humboldt fellows from the USA and Canada worked in the arts and humanities (39.4\%), more than $90 \%$ of Humboldt fellows from South Asia were natural scientists and engineers $(93.7 \%)$. Accordingly, a considerably lower number of researchers from the USA and Canada had published joint publications with colleagues in Germany as a result of their Humboldt stay (59.2\%) than researchers from South Asia (93.5\%). The larger frequency of placespecific practices in the arts and humanities also leads to the apparently contradictory finding that previous to their Humboldt research stay in Germany, more researchers working in these fields had published with colleagues in Germany than among their colleagues in the natural and technical sciences (Fig. 5b-A). Scholars in the arts and humanities often require learning the language of their area of specialisation and thus mostly look back on a history of research stays abroad starting with their PhD if not earlier. Prior to their Humboldt research stay in Germany, more than $80 \%$ of those working on empirical $(95.1 \%)$, argumentative-interpretative $(83.8 \%)$ and theoretical $(87.2 \%)$ projects in the arts and humanities had been to Germany, while this were less than $70 \%$ in the theoretical natural sciences $(65.5 \%)$ and less than $60 \%$ in the experimental natural $(54.9 \%)$, the experimental technical $(51.4 \%)$ and the theoretical technical sciences (35.9\%).

These findings highlight that variations in the spatial relations of different scientific practices tend to cross familiar categories of traditional subjects. Figures $4 \mathrm{~b}$ and $5 \mathrm{~b}$, for example, reveal that theoretical work in the natural sciences, the engineering sciences and the arts and humanities represents the least place-specific practices with the greatest individuality in regard to resulting joint publications. However, these different kinds of theoretical work have also a lot in common with the other types of work inside the respective disciplinary boundaries. The three different types of research work displayed in the arts and humanities, for example, show the largest frequencies of place-specificity and of individuality in regard to resulting joint publications. Therefore, the quantitative data helps to identify and quantify typical features regarding the place-specificity and the collaborative potential of different research practices. However, why do some research practices appear typically to be more place-specific and individual than others - and vice versa? (a)

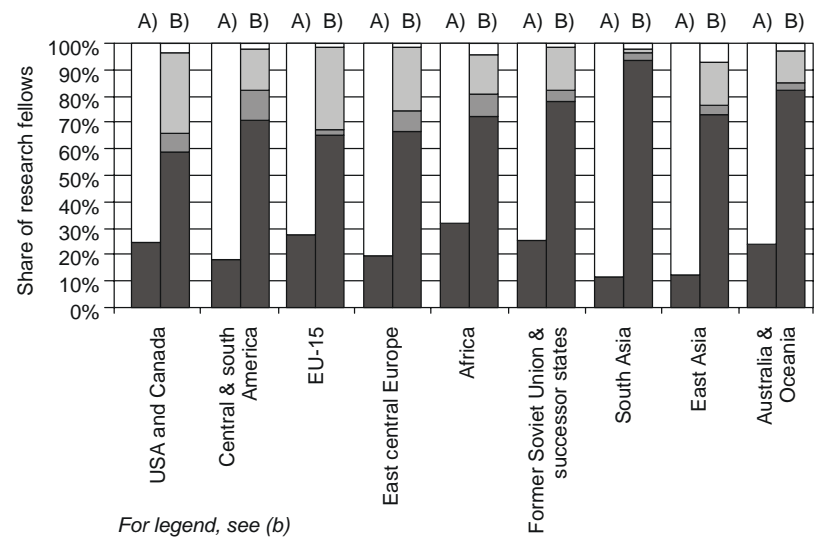

(b)

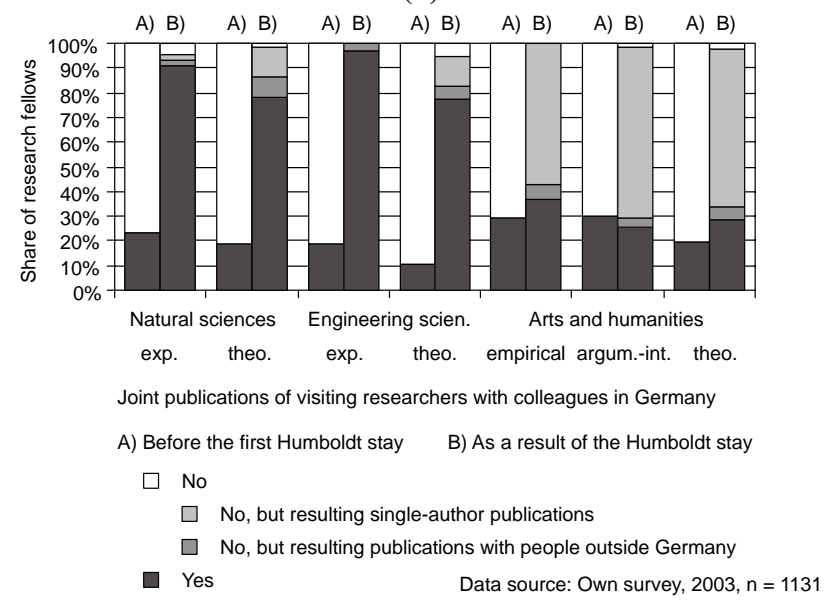

Fig. 5. Joint publications of Humboldt fellows and colleagues in Germany, 1981-2000. (a) By country of origin [statistical significance: A) $* * * ; B) * * *$ ]. (b) By type of work [statistical significance: A) n.s.; B) ***].

\section{Conceptual spaces of knowledge production}

In this final section, I elaborate on the question of how the observed statistical patterns might be explained. The main task will be to construct a conceptual framework, in which different cultures of academic mobility and collaboration that have been identified along the continua of placespecific/ubiquitous and individual/collective research practices are conclusively related to the spatial ontology of these very practices. The focus on practices is conceptually linked to an actor-network based understanding of knowledge production in the sciences as well as in the arts and humanities (Jöns, 2003:156-160). From this point of view, the ontological status of the constituents of scientific practice is altered within the process of network-building, while the resulting facts and artefacts can be regarded as (temporarily) stabilised results of scientific work (Latour, 1992:285-286). They might still be ontologically hybrid in the sense that 
(immaterial) ideas and knowledge claims are always embodied in some kind of physical vehicle (e.g., brain, computer, paper), while (material) artefacts and machines always incorporate some kind of information (Jöns, 2006:573). Based on the empirical findings, however, I argue that different $d e$ grees of materiality and immateriality in scientific practice and interaction imply varying spatial relations, which help to explain a wide range of subject- and method-specific cultures of academic mobility and collaboration.

In this understanding, each material, sociomaterial, mental or human element that constitutes a scientists' web of (well proven) allies and (new) resources is more or less placespecific, i.e. localised in a particular physical and social context (Ophir and Shapin, 1991:9). This place-specificity influences (not determines) a researcher's needs and opportunities to reach out from a place of knowledge production in order to communicate and to interact, to work and to mobilise new resources in other places. As the analysis of motivations for academic mobility showed, there are of course very complex relations at work when it comes to the question of whether a researcher becomes internationally mobile. The wide range of influences included political systems, economic resources, laws, scholarships, past achievements, language skills, academic functions, personal contacts, academic socialisation, cultural affinities and biographical backgrounds, family situation, stage of career, scientific cultures and symbolic hierarchies of centres of calculation (see also Jöns, 2003a:435450). Depending on the researcher's individual position in such networks of heterogeneous resources, his or her behaviour may evade typical patterns in his or her field and type of work. The empirical findings, however, suggest that despite the "double embeddedness" of academic mobility - in the societies involved and in the migrant's life course (King, 2002:101) -, the varying spatial relations of the constitutive elements of academic work are so important that they lead to typical patterns in regard to the place-specificity/ubiquity and individuality/collectivity of knowledge production. In order to account for these patterns, I propose to differentiate three dimensions along which the spatial ontology of scientific practice and interaction may vary.

\section{$6.1(\mathrm{Im})$ materiality}

First, I suggest that the great variety of research practices in the natural sciences, the engineering sciences and the arts and humanities is constituted by elements that differ in their degree of materiality and immateriality. Due to the corporeality of human beings and other "dynamic hybrids", all research practices are to some extent physically embedded and localised (Jöns, 2006). However, researchers working with particular physically embedded material research objects that might not be moved easily, such as archival material, field sites, certain technical equipment, groups of people and events, may be dependent on accessing a particular site or local research context at least once. Those scientists and scholars, who primarily deal with theories and thoughts, are in turn as mobile as the embodiment of these immaterialities allows them to be. This embodiment includes at least themselves, but when the work is also comprised of other researchers, computers and books, any sharp boundaries between higher and lower degrees of (im)materiality may get blurred. The statistics showed that the theoretical work of Humboldt research fellows in the natural sciences would have been much more often possible in a number of different countries than all the other types of work that appeared to be more place-specific as they were more often only possible in Germany (Fig. 4b). Theoretical work in the natural sciences, including, for example, many types of mathematical research, thus appears to be the most "ubiquitous" subject: Its high share of immaterial thought processes compared to relatively few material resources involved in the process of knowledge production (sometimes only pen and paper) would often make it possible, from the perspective of the very practitioners, to work in a number of different places. The first dimension of the proposed three-dimensional conceptual matrix thus positions a great variety of research practices between the two extremes of place-specific and ubiquitous types of academic work resulting from their different degrees of materiality and immateriality.

\subsection{Standardisation}

Second, I propose that the constitutive elements of scientific work vary according to their degree of standardisation. Standardisation results from the work and agreement previously invested in the classification and transformation of things, ideas, people and other organisms. A high degree of standardisation would mean that the research practice relies on many uniform terms, criteria, formulas and data, components and materials, methods, processes and practices that are generally accepted in the particular field of academic work. For example, a field site in the remoter areas of the world might initially show no signs of standardisation through research infrastructure or fences that help to locate the site within well-established world-wide graticules. Laboratory equipment such as test tubes, however, may have been manufactured on the basis of previous - and then standardised considerations and practices. The field site may be unique, the laboratory equipment may be found at several sites to which the networks of science have been extended (Latour, 1987:249). Therefore, field studies and also empirical studies examining authentic life worlds may at least at some point in the process of knowledge production depend on the access to one particular site, while experimental studies in highly standardised laboratory contexts of the physical and biological sciences may be conducted in several places offering the necessary equipment.

However, there are also significant differences in the degree of standardisation when comparing, for example, the constitutive elements of experimental practices in the natural 
and engineering sciences. In engineering, for example, experiments often include fewer standardised elements than in other fields, particularly when the project aims to develop new technologies in a specific context of application (e.g., cooperation with industrial companies; see Jöns, 2003a:362). In chemistry, laboratory contexts are often so standardised that compounds can easily be exchanged between and analysed in different places, which also makes international collaboration much easier (see Jöns, 2003a:443445). Therefore, experimental projects in engineering had more often to be conducted in Germany than experimental projects in the natural sciences (Fig. $4 \mathrm{~b}$ ). The empirical findings also show that experimental practices in both the natural and engineering sciences were more often bound to Germany than their theoretical counterparts. In this case, I would argue, it is not so much a difference in standardisation but the difference in (im)materiality that explains these variations (Fig. 6). This is because theoretical practices in the natural and technical sciences also show a high degree of standardisation when compared to theoretical and argumentativeinterpretative work in the arts and humanities. The latter often relies on the ideas and accounts of individuals and certain schools of thought; it deals with particular histories and geographies in different languages, and thus represents much more frequently very place-specific endeavours. More than $80 \%$ of those scientists working in the theoretical natural sciences stated that they could have done their Humboldt research project outside Germany as well $(82.3 \%)$, while this was only true for $50 \%$ of scholars working in both the argumentative-interpretative and in the theoretical arts and humanities. The second dimension of the proposed threedimensional conceptual matrix thus differentiates between the two extremes of place-specific and ubiquitous types of academic work resulting from their degrees of standardisation, whether this is in the realms of larger degrees of materiality or immateriality.

\subsection{A two-dimensional matrix}

In the resulting two-dimensional matrix on the spatial relations of different research practices, we can locate the empirically observed differences of both the place-specificity of Humboldt research projects and the resulting joint publications with colleagues in Germany (Fig. 6). Empirical work, showing a high degree of materiality and a low degree of standardisation, is most often dependent on one particular site, followed by argumentative-interpretative work, which is characterised by a similar low degree of standardisation but a higher degree of immateriality. Experimental (laboratory) work, showing a high degree of both materiality and standardisation, can often be conducted in several (laboratory) sites, while theoretical work in the natural sciences, involving both a high degree of immateriality and standardisation is most rarely tied to one particular site.

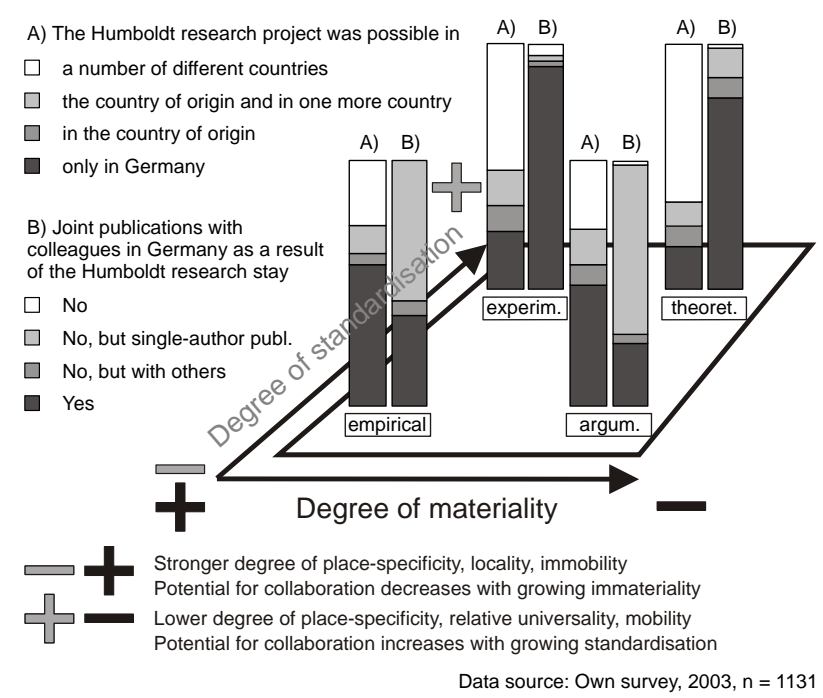

Fig. 6. Theoretical interpretation of empirical results: a twodimensional matrix on varying spatial relations of different research practices (for A see Fig. 4; for B see Fig. 5b-B).

While certain practices in the natural sciences are more standardised than other practices in the natural sciences, similar differences can be observed in the arts and humanities. Including the often more standardised research practices in the social sciences, other branches of the arts and humanities often use less standardised methods and are characterised by a greater meaning of individual language skills than most branches of the social sciences. While particular methods and terminologies have to be learned in all fields, the vocabulary necessary for writing papers seems to be much more limited and standardised (or "technical") in fields such as mathematics, physics and chemistry, and also in certain branches of the social sciences, than in history, philosophy and literature studies. (Rarely standardised) philosophical bodies of work may be so dependent on the language skills, views and reading experiences of an individual that it is difficult to find another individual to work with (among philosophers), while (highly standardised) mathematical discourses may show less signs of individuality and thus a greater connectivity of ideas (among mathematicians). Highly standardised research contexts make it easier to collaborate, even if the researchers had previously not been to the country of their potential collaborators (see Fig. 5b-B and Sect. 5.2).

Collectivity, defined here as an opportunity for collaboration, actually increases with both growing materiality and standardisation (Fig. 6). From the perspective of the researcher, most opportunities for collaboration result from an external (material) research context and a high standardisation of the research practices involved. On the one hand, it is easier to create a common understanding on the basis of visible research contexts, standardised equipment and methods, and a common technical English language. On the 


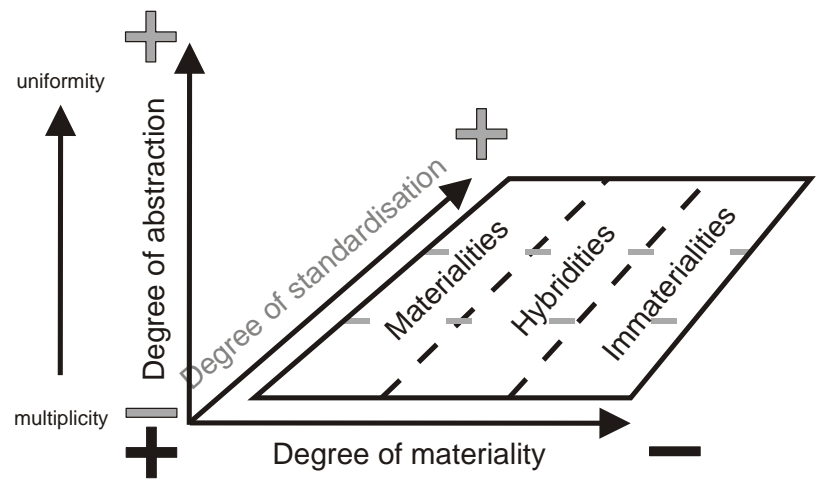

Stronger degree of place-specificity, locality, immobility
Potential for collaboration decreases with growing immateriality

Fig. 7. A three-dimensional matrix on varying spatial relations of scientific practice and interaction.

other hand, the complexity of the equipment and task may require a division of labour, which can be easily arranged on these grounds. The fewest joint publications were written in argumentative-interpretative work, where a large internal (immaterial) research context and a great variety of arguments from different authors in possibly different languages complicate collaboration on a specific topic. To be sure, both internal and external contexts are part of the same actor-networks and thus not possible to separate, but the different degrees of (im)materiality and standardisation suggest that it makes sense to introduce these categories from the perspective of the practitioners in order to better understand the nature of different research practices.

\subsection{Abstraction}

Third, I propose that the spatial relations of different research practices vary at subsequent stages of knowledge production. This argument builds upon Latour's claim that in the course of scientific practice multiplicity gets transformed into uniformity in order to be able to speak about much more complex phenomena in a structured way (Latour, 1999:7073). In this understanding, researchers perform consequential mediations from matter to form involving a trade-off between the loss of multiplicity, materiality and locality and the gain of standardisation, immateriality and relative universality (Latour, 1999:71; Jöns, 2006:571). This means that independent of the ontology of the constituting elements, research practices resemble work of abstraction that proceeds from a stronger place-specificity to a larger ubiquity. Latour (1999) developed his concepts of "chains of transformation" and "circulating reference" between the world (the field site) and words about this world (the resulting paper) by following earth scientists into the field. However, this concept seems also to be applicable to theoretical work, because thoughts and theories can as much be superimposed, com- bined and transformed into new forms as (socio)materialities can be (Latour, 1987:243-247). For example, when mathematicians work on a particular problem, they start with a lot of ideas and possible linkages between a great variety of forms and often end up with a specific set of equations in which only a few elements and well defined linkages are left. While the experimental physicist successively transforms matter (e.g., particle beam collisions) to form (e.g., claims about the properties of the state of matter resulting from these collisions; see Jöns, 2006:570-571), the mathematician's chain involves several transformations from form to form when the multiplicity of ideas gets replaced by a set of well structured ideas. The third dimension of the proposed three-dimensional conceptual matrix thus differentiates strongly and lowly place-specific practices at different stages of scientific network-building. These result from different degrees of abstraction and can be observed with all research practices, whether these show a higher or lower degree of materiality and standardisation.

Processes of abstraction, while being characteristic of scientific research, are strongly linked to different degrees of (im)materiality and standardisation. This is because subsequent stages of research work imply different degrees of abstraction and thus a change in materiality and standardisation (Latour, 1999:71). Scientists and scholars often use the "abstracted" results of their colleagues working in the same or in other academic fields - whether these are arguments, methods, research objects and/or infrastructural elements for constructing their own facts and artefacts. In this new construction process, they start with a lot of heterogeneous resources, which show a higher degree of materiality and a lower degree of standardisation than the "abstracted" end products. The latter might then again contribute to the construction of new facts and artefacts in other times and places. The spatial relations of knowledge production may thus be described by a three-dimensional conceptual matrix (Fig. 7). This conceptual space of knowledge production allows for ample trajectories in a vast universe of research practices and helps to explain typical patterns, or cultures, of academic mobility and collaboration in different fields and at different stages of research work. ${ }^{7}$

\section{Conclusions}

There are different possibilities for exploring the question of how geography matters in the production of academic knowledge - and possibly different answers as well (Powell, 2007). In this paper, I examined this question by looking at academic mobility to Germany in the period 1981 to 2000. Why did the visiting researchers from different countries and academic fields leave their home institution in order to work

\footnotetext{
${ }^{7}$ For a theoretical foundation of the differentiation of materialities, hybridities and immaterialies along an axis of different degrees of (im)materiality, see Jöns (2006).
} 
on a research project in Germany for about a year? Drawing upon three comprehensive sets of data, the first part of the paper reconstructed the complex influences on transnational academic mobility by discussing global patterns of interaction and the travelling researchers' motivations to spent a research stay in Germany. While issues related to political, cultural and geographical proximity as well as socioeconomic disparities have had a strong impact on the global geographies of academic mobility and on individual motivations, both have also varied considerably between different academic fields. Based on the question whether the particular research project conducted in Germany could also have been carried out at home or in other countries, the empirical findings pointed to typical relations in regard to the placespecificity/ubiquity of different research practices: The more immaterial and standardised the practice, the lower was the place-specificity of one's work and the easier it would have been to work elsewhere.

The second part of the paper explored the visitors' research work in Germany by comparing previous and resulting joint publications with colleagues in Germany. The amount of previous collaborations was strongly related to the country of origin, while there were no statistically significant variations between fields and types of work. However, once the researchers were in Germany, their country of origin was much less important for their professional interactions than their field and type of work. The frequency of publications written together with colleagues in Germany as a result of the research stay revealed typical patterns in regard to the collectivity/individuality of knowledge production: The more material and standardised the research practice, the more likely was collaboration with others.

The third part of the paper developed the conceptual explanation of these empirical findings and outlined that in addition to different degrees of (im)materiality and standardisation, a third dimension of varying spatial relations unfolds along subsequent stages of knowledge production. These are characterised by a growing degree of abstraction that is related to a decrease in materiality and an increase in standardisation. To be sure, all research practices produced situated knowledges and were thus shaped by what Gregory (1998:57-58) identified as a "double geography", namely "a hierarchy of spaces of knowledge production in which some sites are valorized as more central than others" and "a hierarchy of sites of study in which some places are valorized as canonical or exotic, as exemplary sites of consuming interest, whereas others are marginalized as merely other, less interesting or less instructive instances of more general conditions that are better exemplified elsewhere". However, while this "double geography" refers to the level of discourses and imaginaries circulating in the academic community (and being materialised in research infrastructure and research money), I argued in this paper that the ontology of the constitutive elements of knowledge producing practices varies in such a way that it implies different spatial relations, which help to explain typical cultures of academic mobility and collaboration in different fields and type of research work. In other words, the argument is that the nature of different types of research practices implies different spatial relations that in turn influence the motivations for and outcomes of academic mobility and collaboration.

In the previous study on academic mobility of US senior scientists to Germany it was only possible to differentiate two dimensions of the conceptual matrix - degrees of (im)materiality and abstraction - because almost all interviewees worked in the natural and technical sciences (Jöns, 2003a:426). In the project discussed in this paper, however, the large number of respondents from across all fields and types of academic work, including the often neglected arts and humanities, helped to identify three dimensions along which the spatial relations of different research practices may vary, thereby producing different geographies in different disciplines and types of research work. As the categories of the questionnaire were constructed out of the experiences of over 60 US senior scientists and then sent out to other former visiting researchers from different countries, the empirical findings presented in this paper provide some kind of validation of the idea that varying spatial relations of different research practices explain typical cultures of academic mobility and collaboration in the context of late-20th-century cross-boundary science.

The proposed conceptual matrix on varying spatial relations of scientific practice and interaction can be linked to other typologies on the relation of knowledge and space. Meusburger (2000), for example, argues that different types of knowledge imply different degrees in the spatial concentration of work places. As different research practices produce different types of knowledge, both phenomena - process and product - seem to relate to typical geographies, whether in regard to place-specificity or spatial concentration. The idea of a matrix of different spatialities has also been developed by Werlen $(1993,2000: 329)$ in the context of his notion of a social theory of action and by Harvey $(2005: 105,111)$ in the context of both a general and a Marxist understanding of society. As Harvey's "general matrix of spatiality" illustrates, his ontological differentiation of material (e.g., mountains and buildings), represented (e.g., maps and cyberspace) and lived space (e.g., memories and feelings) is comparable to the distinction of materialities, hybridities and immaterialities that constitute the research objects of different research practices. All these typologies share a contextspecific and relational understanding of knowledge and space that escapes simple definitions and allows for contingency, complexity and multiplicity within a roughly sketched conceptual framework. They also raise the question about the ways in which varying spatial relations of different practices have shaped the geographies of knowledge in other times and places and in other constitutive realms of what might be called an emerging "knowledge society". 
Acknowledgements. This research was only possible through the cooperation of several people and institutions. I am grateful to the German Research Council (DFG) for funding project ME807-18 Internationale Wissenschaftsbeziehungen; to the Alexander von Humboldt Foundation for kindly providing statistical data on their fellowship programme and for supporting the survey; to thousands of former Humboldt research fellows for participating in the survey; to P. Meusburger for his continued support of this work; to K. Hoyler for transcribing several interviews; to C. Brust, N. Ejiri, K. Lichti, V. Reitz, B. Wünsch and C. Ziechner for feeding the survey data into the computer; and to D. Evans, M. Hoyler and two anonymous referees for helpful comments on an earlier version of this paper.

Edited by: J. Pickles

\section{References}

Ackers, L.: Moving People and Knowledge: Scientific Mobility in the European Union, International Migration, 43, 5, 99-131, 2005.

Ackers, H. L. and Gill, B.: Attracting and Retaining Early Career Researchers in English Higher Education Institutions, Innovation: The European Journal of Social Science Research, 18, 3, 277-299, 2005.

Altbach, P. G.: The New Internationalism: Foreign Students and Scholars, Studies in Higher Education, 14, 2, 125-136, 1989.

Baláz, V. and Williams, A.: Been There Done That: International Student Migration and Human Capital Transfers from the UK to Slovakia, Population, Place and Space, 10, 3, 217-237, 2004.

Barnett, G. A. and Wu, R. Y.: The International Student Exchange Network: 1970 and 1989, Higher Education, 30, 353-368, 1995.

Barnett, R. and Phipps, A.: Academic Travel: Modes and Directions, The Review of Education, Pedagogy, and Cultural Studies, 27, 3, 3-16, 2005.

Becher, T.: Academic Tribes and Territories: Intellectual Enquiry and the Cultures of Disciplines, Open University Press, Milton Keynes, 1989.

Bingham, N. and Thrift, N.: Some New Instructions for Travellers: The Geography of Bruno Latour and Michel Serres, in: Thinking Space, edited by: Crang, M. and Thrift, N., Routledge, London, 281-301, 2000.

Blumenthal, P., Goodwin, C. D., Smith, A., and Teichler, U. (Eds.): Academic Mobility in a Changing World: Regional and Global Trends, Higher Education Policy 29, Jessica Kingsley Publishers, London, 1996.

Budke, A.: Wahrnehmungs- und Handlungsmuster im Kulturkontakt: Studien über Austauschstudenten in wechselnden Kontexten, Osnabrücker Studien zur Geographie 25, Vandenhoeck \& Ruprecht, Göttingen, 2003.

Button, K., Brown, P., Fischer, M., Maggi, R., Ouwersloot, H., Rammer, C., Rietveld, P., and Salomon, I.: Academic Links and Communications, Avebury, Aldershot, 1993.

Crawford, E., Shinn, T., and Sörlin, S. (Eds): Denationalizing Science: The Contexts of International Scientific Practice, Kluwer Academic Publications, Dordrecht, 1993.

Department of Trade and Industry: Knowledge Migrants: The Motivations and Experiences of Professionals in the UK on Work Permits, Department of Trade and Industry, London, 2002.
Ekmann, R. and Quandt, R. (Eds): Technology and Scholarly Communication, University of California Press, Berkeley, CA, 1999.

Enders, J. and Teichler, U.: Academics' Views of Teaching Staff Mobility: The ERASMUS Experience Revisited, in: The Professoriate: Profile of a Profession, edited by: Welch, A., Springer, Dordrecht, 97-112, 2005.

Findlay, A.: Skilled Transients: The Invisible Phenomenon, in: Cambridge Survey of World Migration, edited by: Cohen, R., Cambridge University Press, Cambridge, 515-522, 1996.

Glaser, B. G. and Strauss, A. L.: The Discovery of Grounded Theory, Aldine de Gruyter, Chicago, 1967.

Goodwin, C. D.: Academic Mobility in a Changing World: Concluding Reflections on the Issues at Stakes, in: Academic Mobility in a Changing World: Regional and Global Trends, edited by: Blumenthal, P., Goodwin, C. D., Smith, A., and Teichler, U., Higher Education Policy 29, Jessica Kingsley Publishers, London, 359-368, 1996.

Gregory, D.: The Geographical Discourse of Modernity, in: Explorations in Critical Geography, edited by: Gregory, D., HettnerLecture 1997, Department of Geography, University of Heidelberg, Heidelberg, 45-67, 1998.

Gregory, D.: Cultures of Travel and Spatial Formations of Knowledge, Erdkunde, 54, 4, 297-319, 2000.

Haraway, D.: Situated Knowledges: The Science Question in Feminism and the Privilege of Partial Perspective, in: The Science Studies Reader, edited by: Biagioli, M., Routledge, London, 172-188, [1988]1999.

Harvey, D.: Space as a Key Word, in: Spaces of Neoliberalization: Towards a Theory of Uneven Geographical Development, edited by: Harvey, D., Franz Steiner Verlag, Stuttgart, 93-115, 2005.

Heffernan, M. J.: A State Scholarship: The Political Geography of French International Science during the Nineteenth Century, Transactions, Institute of British-Geographers, 19, 1, 21-45, 1994.

Iredale, R.: The Migration of Professionals: Theories and Typologies, International Migration, 39, 5, 7-26, 2001.

Iredale, R. and Appleyard, R.: International Migration of the Highly Skilled: An Introduction, International Migration, 39, 5, 3-6, 2001.

Jallade, J. P.: Editorial, Special Issue on Student Mobility, European Journal of Education, 31, 2, 131-132, 1996.

Jansen, C.: Exzellenz weltweit: Die Alexander von HumboldtStiftung zwischen Wissenschaftsförderung und auswärtiger Kulturpolitik, DuMont, Köln, 2004.

Jalowiecki, B. and Gorzelak, G. J.: Brain Drain, Brain Gain and Mobility: Theories and Prospective Methods, Higher Education in Europe, 29, 3, 299-308, 2004.

Jöns, H.: Internationalität durch ausländische Gastwissenschaftler, in: Nationalatlas Bundesrepublik Deutschland: Bildung und Kultur, edited by: Institut für Länderkunde, Spektrum Akademischer Verlag, Heidelberg, 84-85, 2002.

Jöns, H. Grenzüberschreitende Mobilität und Kooperation in den Wissenschaften: Deutschlandaufenthalte US-amerikanischer Humboldt-Forschungspreisträger aus einer erweiterten Akteursnetzwerkperspektive, Heidelberger Geographische Arbeiten 116, Selbstverlag des Geographischen Instituts der Universität Heidelberg, Heidelberg, 2003a.

Jöns, H.: Geographies of International Scientific Exchange in their Political Context: The Case of Visiting Scholars to Germany in 
the Second Half of the 20th Century, in: Frontiers of Geography, edited by: Nemes Nagy, J. and Jakobi, Á., Department of Regional Geography, Eötvös Loránd University, Budapest, 227247, 2003b.

Jöns, H.: Academic Mobility and Collaboration Across the Atlantic: Experiences in the Humanities and the Social Sciences, in: What Factors Impact the Internationalization of Scholarship in the Humanities and Social Sciences?, edited by: Humboldt Foundation, Arbeits- und Diskussionspapiere 3, Humboldt Foundation, Bonn, 7-24, 2005.

Jöns, H.: Dynamic Hybrids and the Geographies of Technoscience: Discussing Conceptual Resources Beyond the Human/NonHuman Binary, Social and Cultural Geography, 7, 4, 559-580, 2006.

Jöns, H.: Academic Travel from Cambridge University and the Formation of Centres of Knowledge, 1885-1954, GaWC Research Bulletin 234, http://www.lboro.ac.uk/gawc/rb/rb234.html, 2007.

Jöns, H. and Meusburger, P.: Internationaler Wissenschaftsaustausch, in: Nationalatlas Bundesrepublik Deutschland: Deutschland in der Welt, edited by: Institut für Länderkunde, Spektrum Akademischer Verlag, Heidelberg, 116-119, 2005.

King, R.: Towards a New Map of European Migration, International Journal of Population Geography, 8, 2, 89-106, 2002.

King, R., and Ruiz-Gelices, E.: International Student Migration and the European Year Abroad: Effects on European Identity and Subsequent Migration Behaviour, International Journal of Population Geography, 9, 3, 229-252, 2003.

Koser, K. and Salt, J.: The Geography of Highly Skilled International Migration, International Journal of Population Geography, 3, 285-303, 1997.

Kuhn, T.: The Structure of Scientific Revolutions, University of Chicago Press, Chicago, 1962.

Laudel, G.: Migration Currents Among the Scientific Elite, Minerva, 43, 377-395, 2005.

Latour, B.: Science in Action: How to Follow Scientists and Engineers Through Society, Harvard University Press, Cambridge, MA, 1987.

Latour, B.: "One More Turn after the Social Turn...., in: The Social Dimensions of Science, edited by: McMullin, E., University of Notre Dame Press, Notre Dame, 272-292, 1992.

Latour, B.: On Actor-Network Theory: A Few Clarifications, Soziale Welt, 47, 369-381, 1996.

Latour, B.: Pandora's Hope: Essays on the Reality of Science Studies, Harvard University Press, Cambridge, MA, 1999.

Latour, B.: Reassembling the Social: An Introduction to ActorNetwork-Theory, Oxford University Press, Oxford, 2005.

Law, J. and Hassard, J. (Eds): Actor Network Theory and After, Blackwell, Oxford, 1999.

Li, F. L. N., Findlay, A. M., Jowett, A. J., and Skeldon, R.: Migrating to Learn and Learning to Migrate: A Study of the Experiences and Intentions of International Student Migrants, International Journal of Population Geography, 2, 51-67, 1996.

Livingstone, D. N.: The Spaces of Knowledge: Contributions Towards a Historical Geography of Science, Environment and Planning D: Society and Space, 13, 5-34, 1995.

Livingstone, D. N.: Making Space for Science, Erdkunde, 54, 4, 285-296, 2000.

Livingstone, D. N. (Ed.): Science, Space and Hermeneutics: Hettner-Lecture 2001, Department of Geography, University of
Heidelberg, Heidelberg, 2002a.

Livingstone, D. N.: Knowledge, Space and the Geographies of Science, in: Science, Space and Hermeneutics: Hettner-Lecture 2001, edited by: Livingstone, D. N., Department of Geography, University of Heidelberg, Heidelberg, 7-40, $2002 \mathrm{~b}$.

Livingstone, D. N.: Putting Science in its Place: Geographies of Scientific Knowledge, The University of Chicago Press, Chicago, 2003.

Meusburger, P.: The Spatial Concentration of Knowledge: Some Theoretical Considerations, Erdkunde, 54, 4, 352-364, 2000.

Martin-Rovet, D.: Opportunities for Outstanding Young Scientists in Europe to Create an Independent Research Team, European Science Foundation, Strasbourg, 2003.

Morano-Foadi, S.: Scientific Mobility, Career Progression, and Excellence in the European Research Area, International Migration, 43, 5, 133-162, 2005.

Naylor, S.: Historical Geographies of Science: Places, Contexts, Cartographies: Special Issue on the Historical Geographies of Science, British Journal for the History of Science, 1-12, 2005.

Ophir, A. and Shapin, S.: The Place of Knowledge: A Methodological Survey, Science in Context, 4, 1, 3-21, 1991.

Pethe, H.: Internationale Migration hoch qualifizierter Arbeitskräfte: Die Greencard-Regelung in Deutschland, Deutscher Universitäts-Verlag, Wiesbaden, 2006.

Powell, R. C.: Geographies of Science: Histories, Localities, Practices, Futures, Progress in Human Geography, 31, 309-329, 2007.

Salt, J.: International Movements of the Highly Skilled, OECD Working Papers 91, OECD, Paris, 1997.

Shapin, S.: Here and Everywhere: Sociology of Scientific Knowledge, Annual Review of Sociology, 21, 289-321, 1995.

Smith, C. and Agar, J. (Eds): Making Space for Science: Territorial Themes in the Shaping of Knowledge, MacMillan, Basingstoke, 1998.

Taylor, P. J., Hoyler, M., and Evans, D. M.: A Geohistorical Study of the Rise of Modern Science: Career Paths of Leading Scientists in Urban Networks, 1500-1900, GaWC Research Bulletin 233, http://www.lboro.ac.uk/gawc/rb/rb233.html, 2007.

Teichler, U.: Research on Academic Mobility and International Cooperation in Higher Education: An Agenda for the Future, in: Academic Mobility in a Changing World: Regional and Global Trends, edited by: Blumenthal, P., Goodwin, C. D., Smith, A., Teichler, U., Higher Education Policy 29, Jessica Kingsley Publishers, London, 338-358, 1996.

Teichler, U. (Ed.): ERASMUS in the SOCRATES Programme: Findings of an Evaluation Study, ACA Papers on International Cooperation in Education, Lemmens, Bonn, 2002.

Universities UK (Ed.): Talent Wars: The International Market for Academic Staff, Universities UK, London, 2007.

OECD (Ed.): Internationalisation of Higher Education, OECD Documents, Centre for Educational Research and Innovation, OECD, Paris, 1996.

OECD (Ed.): Internationalisation and Trade in Higher Education: Opportunities and Challenges, Centre for Educational Research and Innovation, OECD, Paris, 2004.

Van de Sande, D., Ackers, H. L., and Gill, B.: Impact Assessment of the Marie Curie Fellowships under the 4th and 5th Framework Programmes of Research and Technological Development of the EU (1994-2002), European Commission, Brussels, 2005. 
Wagner, C. S.: Six Case Studies of International Collaboration in Science, Scientometrics, 62, 1, 3-26, 2005.

Wagner, C. S. and Leydesdorff, L.: Mapping the Network of Global Science: Comparing International Co-authorships from 1990 to 2000, International Journal of Technology and Globalization, 1, 2, 185-208, 2005a.

Wagner, C. S. and Leydesdorff, L.: Network Structure, SelfOrganization, and the Growth of International Collaboration in Science, Research Policy, 34, 10, 1608-1618, 2005 b.

Weingart, P.: Wissenschaft und Forschung, in: Handwörterbuch zur Gesellschaft Deutschlands, edited by: Schäfers, B. and Zapf, W., Leske \& Budrich, Opladen, 720-731, 1998.
Werlen, B.: Society, Action and Space: An Alternative Human Geography, Routledge, New York, 1993.

Werlen, B.: Sozialgeographie, UTB für Wissenschaft, Haupt, Bern, 2000.

Windham, D. M.: Overview and Main Conclusions of the Seminar, in: Internationalisation of Higher Education, edited by: OECD, OECD Documents, OECD, Paris, 7-29, 1996. 